\title{
Can Project Alliance Contracts Deliver Australia's National Broadband Network?
}

Marianne Rose ${ }^{1}$, (The University of Melbourne / DLA Piper, Australia)

\begin{abstract}
The Australian Government has commenced an 8-year project to build and operate a new super-fast broadband network. This $\$ 43$ billion dollar project aims to connect $90 \%$ of Australians to a $100 \mathrm{Mbps}$ broadband service. Given the uncertainties associated with the project, this paper argues that an alliance contract structure is a suitable model for the delivery of the National Broadband Network.
\end{abstract}

\section{Introduction: Understanding the Government's Aspirations to Build a Fast-paced Digital Economy}

A change is taking place in the Australian broadband landscape. The Australian Government has established the company NBN Co Limited (NBN Co) to build and operate a new superfast broadband network. This $\$ 43$ billion dollar, 8-year project aims to connect $90 \%$ of Australian homes, schools and businesses to a $100 \mathrm{Mbps}$ broadband service (Prime Minister et al. 2009a, http://www.minister.dbcde.gov.au/media/media releases/2009/022). However, in the context of a mass infrastructure project can the National Broadband Network ('NBN') be the foundation stone of the digital economy if it is without a contractual model to bind its framework together? This article considers if the alliance contract model can provide a legal framework to enable the deployment and delivery of an optical fibre broadband network to create the highway to Australia's fast-paced digital future.

The NBN project is accumulating debt, while demanding resources to ensure the delivery of a ubiquitous optical fibre network. If it succeeds, it will be the largest infrastructure project in Australian history; and yet it has no transparent contractual model to allocate risks and responsibilities in the delivery and deployment of the project. In order for the NBN roll-out to succeed, a clear, publicly available contractual framework must be established; one that defines the contractual model to be used, and appropriately allocates risk in order to manage a project of this magnitude.

At the time of writing the Government has not publicly articulated the contractual model or risk allocation framework it intends to use. Instead, the Government maintains a view that it will learn as each stage is rolled out (DBCDE 2010, http://www.nbnco.com.au/assets/mediareleases/2010/secon d -release-08-jul-10.pdf). This paper submits that the alliance contract model could aid this ambitious project in an area where little to no transparent discussion exists. During the course of this discussion, the historical context, deliverables and contractual structure will be examined to suggest why the alliance contract model would be the most appropriate for the roll-out of the broadband network. It will be contended that the flexible management structure and ability to adapt to changes in scope of works of an alliance structure, which promotes no fixed cost open pricing and based on project costs and overheads, and internally dispute resolution without referral to a court, usually seen in construction projects makes Alliances a viable model. 


\title{
Historical Development: Foundations of the NBN
}

The NBN falls under the auspices of the Department of Broadband, Communication and the Digital Economy ('DBCDE'), Bentley (2009, p. 15) cites the DBCDE as a Department striving to create:

\begin{abstract}
a world-class Australian communications and information technology sector [that] will build on the creativity of our people and the opportunities provided by new technologies to enrich the economic and social wellbeing of all Australians.
\end{abstract}

The purpose of the NBN is to provide a technological platform whereby the future of Australia's smart infrastructure is shaped by e-health systems, e-commerce, and a 'digital education revolution'. The complexity in delivering the fibre optic broadband infrastructure for $\$ 43 b i l l i o n$ in 8 years is primarily the size of the project, and simply whether it can be delivered on time and within budget.

\section{The Historical Context of the NBN and the Current Regime}

In 1997, the Australian telecommunications industry was deregulated through the passage of the Telecommunications Act 1997 (Cth), and Part XIB and XIC of the Trade Practices Act 1974 (Cth). These acts removed competition restrictions placed on carriage services providers and encouraged the supply and promotion of innovative and responsive telecommunications services to consumers. With the public listing of Telstra in 1997, the Australian telecommunications landscape became synonymous with the monopoly wholesaler. It is Telstra that owns the ubiquitous copper network that presently services Australians with telephony and internet.

As part of the 2007 election campaign the then opposition leader, Kevin Rudd included in his political platform a proposal for a NBN. This proposal competed with the incumbent Liberal Government's \$958 million Australia Connected package. Under this package, the Howard Government awarded the Optus and Elders joint venture, OPEL Networks Pty Ltd ('OPEL') a contract to connect 1 million rural and remote premises with metropolitan comparable broadband services (Optus 2007a, http://www.optus.com.au/aboutoptus/About+Optus/ Media+Centre/Media+Releases/2007/Elders+and+Optus+to+build+rural+and+regional+broa dband+network ).

Following the Australian Labor Party's win in the 2007 Federal Election, this contract was promptly withdrawn when the new Government came to power. Immediately, the new Government commenced a Request for Proposals ('RFP') to build a comprehensive broadband network. A number of candidates submitted proposals, including Telstra, whose submission was rejected because it did not comply with the terms. However, this process was abandoned in April 2009 on the advice of the Independent Panel of Experts because no suitable candidates offered value for money. Despite the RFP's termination, the Government proceeded to fast-track negotiations with the Tasmanian Government for the construction of the NBN in Tasmania. This was because of the Independent Panel of Experts advice that Tasmanians were faced with significant disadvantages when accessing high-speed broadband (Prime Minister et al. 2009b http://www.minister.dbcde.gov.au/media/media releases/2009/023, Prime Minister et al. 2009c, Error! Hyperlink reference not valid.).

Interestingly, the decision to terminate the RFP process coincided with the deterioration of the global economy and one can question whether the RFP participants' could have succeeded under those conditions. The termination of the tender led to the creation of NBN Co. With the establishment of NBN Co, the broadband network would be built on behalf of the Government and operated as a wholesale-only fibre network (Liew 2009, p. 19). This network would be designed to service $90 \%$ of the population with Fibre-to-the-Premises ('FTTP') coverage; enabling Australians to enter the fast-paced digital future. 
With the Government's announcement that NBN would undertake the project, it commissioned McKinsey-KPMG to examine the projects viability through an 'Implementation Study' (DBCDE, 2010). At the same time, the Liberal party dominated Senate Select Committee on the National Broadband Network that was established to inquire into the project. The short timeframe in which the project and NBN Co were brought to life, and the vast scope of work demanded under the NBN project, has seen developments occur on an apparently ad hoc basis and with a lack of operational planning (Senate Select Committee on the National Broadband Network 2010d, p.9). Similarly, the contractual framework was cloaked in confidentiality and remains largely unaccountable or referenced by either the Implementation Study (DBCDE, 2010) or the Senate Select Committee (Select Committee on the National Broadband Network 2010d). Despite the dynamic history surrounding the project, the current regime may suggest some preferences for a contract model that is flexible in relation to change and costing and is non-adversarial.

\section{Telstra's Monopoly and the Financial Heads of Agreement with the Government}

Under the current regulatory regime, Telstra provides the majority of broadband service by means of telephone exchanges and copper phone lines. It is the antiquated copper line system that the optical fibre will replace as the means of delivering high-speed broadband to consumers. With Telstra having monopoly control of the wholesale infrastructure and therefore power over the quality, maintenance and provision of the majority of the wholesale services, this structure has led to a lack of competition and underinvestment. The common example provided is that this under-pricing of access created a disincentive for Optus to invest in its own hybrid fibre-coaxial ('HFC') network (Liew 2009, pp. 19-20). Instead, Optus chose to utilise the Telstra copper network for less than the price of upgrading its own network. The limited competition undermined the incentive for having Australia-wide market penetration and exacerbated the continuance of an expensive and relatively slow broadband network.

Telstra owns significant assets and infrastructure, comprising of ducts, pits, poles and backhaul. In order to reduce costs for the broadband build, it was in the Government's interests to negotiate with Telstra to gain access to this infrastructure. Although, the Government indicated it was willing to 'go it alone' (DBCDE 2010, pp. 397-398) if it could not reach a commercially and operationally viable agreement, on 20 June 2010 the Rudd Government surprisingly announced that it had entered into a Financial Heads of Agreement with Telstra worth $\$ 11$ billion. This agreement preceded the sudden announcement 4 days later that Julia Gillard was the new Labor leader and Prime Minister of Australia. How this chain of events will affect the NBN project continues to unfold. However, prior to the deal being negotiated, the predominate suggestion was that if Telstra cooperated with NBN Co then $\$ 8$ billion in project costs could be saved. This amount was broken down into a saving of $\$ 5$ billion for the build to use the ducts and dark fibre, plus incentive payments of $\$ 2.5$ billion to migrate customers to the NBN network (Select Committee on the National Broadband Network 2010e). Interestingly, this assessment appears to be based upon a presumption about the quality of the copper network despite the Government's comments that information about the quality of the network is still subject to discussions under a commercial agreement (Select Committee on the National Broadband Network 2010d, pp.47, 74-75).

The Heads of Agreement suggests that Telstra will receive $\$ 9$ billion in compensation for cooperating with the NBN development (Lynch 2010, p. 30). The compensation provides for Telstra to decommission its network and to migrate its customer traffic onto the NBN. It appears that just over half of this figure will account for the reuse of existing fit-for-use infrastructure, such as backhaul fibre, pits, ducts and conduits The CEO of NBN Co, Mr Mike Quigley (NBN Co, 2010b,Error! Hyperlink reference not valid. 
http://www.nbnco.com.au/assets/media-releases/2010/nbnco-media-release-telstra-headsof-agreement-20-jun-10.pdf) emphasised that:

While there is a considerable amount of negotiation and contractual work to go, we believe this agreement is a significant step forward to creating a more competitive telecommunications industry.

This subtle acknowledgement that the contractual framework remains unfinished was rapidly followed up with the announcement on 24 June 2010 that 21 companies had been named to tender for the design and construction of the project (Wilton 2010, p.3779).

The Implementation Study and the Senate Select Committee's Review of the Viability and Risks of the NBN project

The Government commissioned Implementation Study (DBCDE, 2010) by McKinsey-KPMG was released on 6 May 2010, a little over a year since a Government media release announced the plans for the NBN. The Implementation Study was disseminated only one week prior to the planned release of the Senate Select Committee's report into the feasibility of the project. Instead, the Senate Select Committee was compelled to delay its report until 17 June 2010, (Select Committee on the National Broadband Network 2010d). Both these reports were designed to analyse the risks and benefits of the NBN project.

The Implementation Study's 'conservative' analysis estimates that the project could be rolled out over 8 years with a projected cost of $\$ 42.8$ billion; this figure is reduced from the Government's initial estimate of $\$ 43$ billion. It goes on to recommend that NBN Co could provide FTTP coverage to $93 \%$ of premises while the $7 \%$ of premises that fall outside the fibre footprint would be services by fixed-wireless and satellite services, using at least two Ka-band satellites. Suggesting an additional $3 \%$ of premises could access the optical fibre network within the projects estimated cost (DBCDE, 2010).

In contrast, the adversarial Senate Select Committee highlights that the Government and NBN Co, in its delivery of the project, have made some significant and potentially irreversible decision on the network architecture and product offering. It also suggested that as in Tasmania, industry stakeholders, potential customers and telecommunications analysts are being left without information or guidance on key aspects of the plan (Select Committee on the National Broadband Network 2010e, p.9.), especially in relation to how the project will be delivered and risks managed.

Unsurprisingly, the Liberal-dominated Senate Select Committee was critical of the Government's plan emphasising that the:

Implementation Study is an exercise in retrofitting a justification for the Government's commitment rather than adequately explaining how the NBN can and/or should be implemented (Select Committee on the National Broadband Network 2010e p 9).

Neither Study comments in detail about the lack of contractual transparency surrounding the model, both seemingly accepting NBN Co would provide this, despite their scope being to evaluate Government policy, review the decision to implement the project and conduct a cost-benefit analysis (Select Committee on the National Broadband Network 2010d, p. 8, e, p.9). However, before a contract model can be chosen, it must first be considered what needs to be built.

\section{NBN Today}

Just shy of one year on, NBN Co confirmed on 1 April 2011 that it was suspending the tender process in the view that terms and prices were unacceptable after four rounds of

Rose, M (2011) 'Can project alliance contracts deliver Australia's national broadband network?', Australasian Journal of Construction Economics and Building, 11 (3) 68-81 
negotiations (NBN Co 2011c, http://www.nbnco.com.au/news-and-events/news/nbn-colooks-for-greater-value-from-construction-tender.html). Around the same time on 12 April 2011 the National Broadband Network Companies Act 2011, which provides the regulatory framework for the NBN came into force. Instead NBN Co reached agreement with Silcar to design and construct the deployment of optic fibre for $\$ 380$ million over the next two years (NBN Co 2011b, http://www.nbnco.com.au/news-and-events/news/nbnco-silcar-reachagreement-to-deliver-value-for-money-fibre-rollout.html). Shortly thereafter, on 23 June 2011, NBN Co and Telstra announced they had signed the Definitive Agreement to enable the roll out of the NBN, subject to ACCC and shareholder approval on 18 October 2011 (Telstra 2011, http://www.telstra.com.au/abouttelstra/download/document/tls795-nom-emvoting.pdf). The same day NBN Co announced it had also reached agreement with Optus, whereby Optus would pay approximately $\$ 800$ million over time to migrate Optus' HFC customers to the NBN (NBN Co 2011a, http://www.nbnco.com.au/news-and-events/news/ nbn-co--optus-sign-binding-agreement.html). Despite the regulatory framework, high level agreements and the release of two major government reports, the lack of information available in the public domain suggests that NBN Co is no closer to articulating a transparent and viable contractual framework for the roll out of the NBN.

\section{Layering the Foundations: How the NBN works}

In order to physically build and then provide broadband applications and services to consumers, contractual structure and consideration needs to be applied to the NBN project.

\section{What Work Needs to be Delivered and Deployed to Build the Broadband Network}

In terms of delivering a fast broadband service to consumers, the NBN will need to build and deliver a working physical network of optical fibres across the country. For the consumer, this deliverable will be experienced as fast internet and multi-user applications on a scale unseen before in Australia. To deliver this, NBN Co and service providers will need to invest in infrastructure and services that will allow the data packets of information to be delivered at fast speed to the end-user. Part of the contractual framework yet to be clarified is who will be responsible for the design and deployment of this infrastructure that enables the data packets of information to reach the end-user? This section will look the physical infrastructure requirements needed to deliver the information to the homes and businesses of Australians.

\section{Layering the Physical Infrastructure}

The infrastructure required to build the network commences with the building of a physical network to deliver communications and computer services across the broadband network. This infrastructure comprises a number of 'layers'. The bottom layer, or 'Layer 1', is the primary physical layer that incorporates the 'dark fibre'. This layer incorporates the physical deployment of the ducts, trenches and poles across the network. The physical infrastructure that will be built, or utilised from Telstra, is anticipated that have a lifecycle of 30-60 years (DBCDE 2010, p. 47). It is this layer that needs to be contracted and built to enable the end services to be delivered.

The optical fibre network proposed by the Government will allow laser light to be shone down thin glass or plastic strands. The second layer, 'Layer 2', is the active equipment that lights the fibres. This is where the active electronic components carry the intelligent 'bits' of information, the base unit of data measurement for computers and the internet, across the fibre via an Ethernet connection (DBCDE 2010, p. 155). The bit is the code that enables computers to calculate, write and store information. Although further layers exist, for the purposes of this discussion the last layer is Layer 3. This is the network layer that provisions the fibre that allows data to be transmitted between nodes enabling retail services, such as the internet, to be supplied to the end-user.

Rose, M (2011) 'Can project alliance contracts deliver Australia's national broadband network?', Australasian Journal of Construction Economics and Building, 11 (3) 68-81 
By recommending that NBN Co only offer Layer 2 bitstream services (DBCDE 2010, pp. 2629 ), it will be the role of Retail Service Providers ('RSP') to provide equipment to consumers to allow for meaningful end-user application such as voice, video and broadband internet. However, the Government envisages that NBN Co will have the capacity to provide Layer 3 services, mostly in relation to wireless and satellite market, to consumers.

To design and build these layers, NBN will need to tender and contract a number of participants. It appears likely it will also incorporate the use of Telstra's existing network. To build the physical network, these contracts will need to be coordinated with contracts that provide the Fibre-to-the-Premises ('FTTP') to the home or business to ensure that rights and obligations to provide a working end service are complementary rather than competing.

\section{FTTP - Ensuring the Network Reaches the Premises}

The NBN is being designed as a FTTP network. This means that the optical fibre will terminate either at the home or living space, the Fibre-to-the-Home ('FTTH') or at the boundary of a building, the Fibre-to-the-Building ('FTTB'), such as in the basement of a Multi-Dwelling Units ('MDU'). This means the optical fibre cable network that reaches the premises will allow multiple homes and business to share local area fibre, through the use of Gigabit Passive Optical Network ('GPON'). This will enable one computer to send data to another, and will enable an end-user, simultaneously, to use phones, computers and highdefinition television (DBCDE 2011d, http://www.nbn.gov.au/for-households/why-is-it-impor $\underline{\operatorname{tant} /)}$.

\section{GPON - Connecting the Fibre to the Premises}

There are two methods that allow for the delivery of fibre into a consumer's home or business; GPON and Point-to-Point. GPON can be used to connect up to 32 or 64 houses in a neighbourhood. This is achieved by connecting a single fibre to a side unit in a street and then splitting the light into fibres that directly connect to a person's home. In contrast, Pointto-Point connects individual fibres directly with each premises and runs from the main exchange to smaller exchanges in a street. The active electronic equipment in the mini exchange can allow approximately 100 premises to be connected. It is likely that the NBN will utilise a mixture of both methods despite GPON being considered the more cost effective option because it minimizes the amount of fibre used, thereby saving costs. It is likely that point-to-point would be more appropriate for businesses and high density residential areas because it allows for high speed delivery (Heydon 2009d, _Error! Hyperlink reference not valid., DBCDE 2010, p. 192).

Until such time as the contractual documents are transparently available, there will remain limited clarity surrounding the integration and deployment of the physical infrastructure around Australia that is required over the next 8 years to implement this project. The construction methods required for this integration will need not only to consider customer needs but differing geography, weather conditions and technical solutions, to name a few concerns. To clarify how NBN Co will deliver the service to the consumer will require a contract structure that is flexible in relation to variations and risk management, open to how costs are calculated and not prone to competing legal claims about responsibility during the build.

\section{Building the Network - What Work Needs to be Delivered to Provide Broadband to Consumers?}

NBN Co will not be providing all the fibre and related infrastructure under the construction its role is more limited. This means it is paramount to clarify the contractual and risk structure, because even though NBN Co intends to offer the fibre service between the Point of Interconnection ('Pol') and the end-user's premises, this does not explain who is

Rose, M (2011) 'Can project alliance contracts deliver Australia's national broadband network?', Australasian Journal of Construction Economics and Building, 11 (3) 68-81 
responsible for ensuring the service works. By providing the Pol, NBN Co will allow the RSP and Wholesale Service Provider (WSP) to connect to the network, allowing the transport and application of content, such as email, to be provided to consumers. It is NBN Co's intention that services will cease at the Pol and the end-user will connect to the network with the use of the backhaul services of existing RSPs and or WSPs (Select Committee on the National Broadband Network 2010d p. 52). NBN Co will then service the Fibre Serving Area ('FSA'), which runs from the end-user's premises to a Fibre Access Node ('FAN'). The FAN or fibre exchange houses the active equipment, and its function is analogous to the copper network. This facility will store the active equipment that provides the network services to the FSA. The remainder of the network will be serviced by infrastructure owned and provided by the RSPs or WSPs.

The two principle users of backhaul are RSPs and WSPs who deliver the 'value add' to consumers. Backhaul capacity is essential to delivering the retail broadband services because it is the means available to connect the service provider's network to the point of service delivery, for example, the connection of the copper network exchanges to mobile towers. However, to activate the service to a premise, NBN Co would be required to lay fibre down the street, bring the fibre to the side of the building; this final cable run is called the drop. The Optical Network Terminal ('ONT') is a device that allows optical fibre to deliver different connection types, such as telephony, internet, television, and is powered in a similar way to a DSL modem. NBN Co (or a nominated contractor) would install an ONT either side of, or inside, a building. In order to connect the premises to FTTP network NBN Co needs to enter the relevant land and install the drop cable and ONT. Once the ONT is live, the RSP can activate the services. This will allow telephones, computers, and other end-user devices to be serviced by ultrafast broadband (DBCDE 2011d).

This infrastructure will require a vast amount of construction and resources, and also carries with it the underlying assumption that optical fibre is the superior technology of choice, and the offer of increased speed and bandwidth will drive the Australian public to take up the NBN. Seemingly unquestioned is whether this will remain the case as new technology or applications emerge with increasing rapidity. A flexible contract model is required to ensure variations that allow new information to be quickly and cost efficiently translated into an agreement between NBN Co and various nominated contractors. It remains publicly unclear how the tender process will be undertaken and how these bids will be able to cost and quote for the work because there seems no ability to quote a lump sum fixed price for the work required under the project. There is added uncertainty as to how this would be rolled out around Australia, particularly if physical and manual resources are scarce. The Implementation Study has not answered questions such as whether the same contractor is responsible for the trenching and the computer functioning, and who is responsible for the delay if the telephony is faulty or not provisioned under the Customer Services Guarantee ('CSG'). This leaves open the question of how the deliverables are packaged and provided. Likewise, the issue of liability remains unresolved because no transparent discussion has taken place concerning who is responsible for problems that arise out of the design, the deployment of fibre or the integration of computers onto the network. While the physical and practical delivery of the project highlights the need for a flexible contract model that allows for variations and does not demand a fixed sum, there remains an absence of contractual detail to clarify the type of contract that would suit these needs.

\section{Contracting for the NBN: Can Alliance Contracts Support the Deployment and Delivery of the NBN?}

In the context of the NBN, this large infrastructure project requires contractual mechanisms to support the deployment and delivery of the project. By being flexible in the manner it manages people and scope changes, by containing the price of the project and assets through the procurement of goods and services, and by internalising disputes to reduce lengthy and costly court proceedings, contracts are best able to contain risk and deliver the

Rose, M (2011) 'Can project alliance contracts deliver Australia's national broadband network?', Australasian Journal of Construction Economics and Building, 11 (3) 68-81 
project on time. In the absence of a transparent contract structure, a viable framework to deliver the NBN project would be the alliance contract model.

\section{The Panacea of Alliancing}

There has been a recent increase at the Commonwealth and State level in the use and encouragement of alliancing to deliver major complex projects. This encouragement of the use of alliancing, and its core concepts of flexible management, design change, pricing and dispute resolution, provide an alternate to traditional forms of contracting and is the reason why it is worthy of discussion as an alternative contract model for the NBN. While alliancing falls into two distinct categories, 'pure' project alliances and 'impure' strategic alliances, it is project alliancing that has been envisaged by this article as a promising solution for contracting under the NBN.

\section{Why the Project Alliance Model Supports the NBN's Objectives}

The brief of NBN Co is to design and build a ubiquitous optical fibre broadband network. The project alliance model is an optimal framework under which to contract the NBN because it overcomes three key hurdles that may hinder the project:

1. The risk of fundamental change to design requirements causing disunity, delay and increased cost to the project

2. Fixed cost for work performed where the scope of work may be uncertain, and

3. Resolution of disputes through the courts that may cause delay and increase costs.

These three hurdles are not conducive to the Government's aspirations for the NBN and could be countered in an alliance agreement through:

1. Flexibility to adapt to change of requirements and through shared responsibility

2. Open-book compensation, and

3. Non-adversarial dispute resolution.

These features under the project alliance model are beneficial for a project like the NBN because a lack of flexibility to vary or change the scope of the project will not allow participants to learn as they go without being penalised for variations. Similarly, a lack of coordinated management will mean participants fail to take collective responsibility for risks, and opportunities, associated with the project. Likewise, a fixed price contract model means that price competitiveness will overshadow project outcomes. This means that the aims envisaged by the Government under the project will be overshadowed by tenders that are cost minimal compared to outcome practicable. Moreover, in the absence of a mechanism to control lengthy and costly disputes over rights and obligations, disagreements should be managed internally to ensure that project delay and taxpayer costs are minimised.

\section{Three Illustrations of How Alliancing may be Advantageous to the NBN Framework}

The three reasons highlighted above of flexibility, open-book accounting and no disputes, are by no means the only hurdles the project will need to overcome. However, in the absence of a contract model these three aspects may be desirable grounds on which to consider the suitability of the project alliance contract model.

\section{Flexibility to adapt to change of requirements and share responsibility}

When considering flexibility, discussion turns to the sharing of collective responsibility between the parties for risk. The success of this project may depend on the ability of participants to vary the scope of the contract design and integrate their teams to distribute risk accordingly. 
Contracts typically define the scope of the project. The role of NBN Co will require different methods of establishment, structure and operation to be undertaken and altered as the needs of the project dictate. This means that the alliance project will need to incorporate a contractual mechanism that will allows each specific project to be varied to suit the design needs, size, location and culture of participants.

Compared to other large-scale projects, the NBN is unique because the roll-out of the NBN is a repetitive project, tailored to the geographical needs of the location. It will need to manage the legacy copper network and the migration of consumers from Telstra to NBN. The work required to deploy fibre or build a wireless tower is similar and the roll-out will take the form of a street-by-street, town-by-town process. It will allow the opportunity to trial new deployment techniques over time, and also presumes that a large number of civil works constructors and equipment vendors will want to be part of the project - which will drive compensative tension, improve productivity and bring down costs.

An alliance contract could also reduce the duplication of general administration and supervision costs that NBN Co will face. This is because there is no duplication of the services or document control because there are no separate client or contract teams with whom to liaise. A contributor to this reduction in cost is the improved cooperation between designers and builders, who can coordinate their work together on the design and construction drawing thus reducing examination hours. By integrating participants, NBN Co could spend less time on site, reduce the materials used and improve the quality of the site by eliminating the need for large project teams at site inspections.

If the Government and NBN Co utilised the alliance model, participants of this project would share governance and management decisions on a 'best for job' basis. The difficulty in gauging success will ultimately turn on whether individual team members fit together. This is a difficult question that is hard to quantify as team environments will change over time through natural attrition. However, by relying on 'management and remuneration structures [to compel participants to] adopt(ed) alliance-style behaviours, but with a less radical approach to risk assumption and liability' (Chew 2004, pp. 323-324) a flexible and cooperative contract structure is designed. This would allow NBN Co to offer an integrated management structure that utilises a board, management team and development project team to resolve reporting, management and dispute resolution issues. Participants could then be remunerated using performance-based on key performance indicators ('KPIs') mechanisms. This structure could allow the incorporation of an obligation for participants to cooperate and act in good faith.

This is consistent with the Government's tender initially being released to 21 participants, because it recognises that the winning participants would initially need to engage with each other if the construction was to complement the Government's goal of learning from one another. Similarly, it would also suit the Silcar agreement and Silcar's subsequent negotiations with subcontractors. For example, latent conditions may exist where NBN Co asks contractors to trench new cabling areas where it cannot access Telstra's pits and trenches. This is a risk that the contractor would normally be required to solely assume. Contractors may not be amenable to that risk where trenching is required at multiple locations with unknown latent risks. By sharing risk responsibility, the contractor has the comfort of knowing they will not be adversely cost affected and NBN Co would know that there would be a provider willing to undertake the work. The decision to allow this would be based on unanimous consideration taken by a jointly managed project management team that is comprised of members who are chosen and allocated for the tasks on a best-fit basis. Disputes can then be resolved within the alliance by escalation up the leadership chain. This style of management would limit costs through participant and open-book accounting and provide no recourse to litigation except in cases of 'wilful default'.

Rose, M (2011) 'Can project alliance contracts deliver Australia's national broadband network?', Australasian Journal of Construction Economics and Building, 11 (3) 68-81 


\section{Open-book compensation}

The $100 \%$ open-book compensation model overcomes the dilemma of how participants cost and quote for work where there is no lump sum price certainty or assess-ability because of project conditions, such as the geographical changes under the NBN. The alliance model provides another means to cost price by removing the need for a lump sum fixed price under the contract. Under an alliance contract, project cost transactions would be validated by an independent auditor, and compensation would be determined by the three limb principles of open-book compensations. The first limb is that project costs and project specific overheads are reimbursed. This is based on an audited scale of actual cost, which means that any costs for rework are included in this price. These costs are completely open and auditable amounts. They include the costing for the delivery schedules, quality and performance. The second limb ensures that a fee is provided to cover corporate overheads and a 'normal' profit. The third limb allows for 'pain' and 'gain' to be equitably distributed. This means that depending on how the project compares to pre-agreed targets then parties are committed to share in any profit or loss. Meanwhile, non-owner participants' loss would normally be limited to corporate overheads and normal profit.

\section{Non-adversarial resolution of disputes}

Since the late 1980s, disputes have been viewed as an endemic part of the construction industry. A risk the NBN faces is where disputes arise concerning whose responsibility it is to undertake an action. For example, regardless of the quality of the contractual drafting, questions might arise surrounding the responsibilities between the participants to ensure the seamless integration of the design, trenching, laying of the fibre, assimilation of computers, packaging of the service and functioning of computers. Without something beyond the contract to ensure the end deliverable of fast broadband to consumers is provided, the project could collapse under the pressures of litigation. For a project of this scale, something more than contractual drafting might be required; it may need good faith that fosters an environment where non-adversarial resolution of disputes and cooperation is encouraged. The alliance model is such a mechanism because it encourages disputes to be managed internally and only allows for a limited right of action between the parties.

Project alliancing adopts a more commercially and legally robust approach to the ideas behind partnering (Jones 2001, p. 155). It seeks to align commercial considerations with a 'no blame, no dispute' culture (Jones 2001, p. 155; Thomas 2007, p. 329). The advantage of a project alliance is that it is specifically designed to share the benefits of the contract amongst the parties to it. This modern method to design, contract and maintain would suggests that parties benefit under this contractual structure because participants commit themselves to what would otherwise be unachievable. This is because consultants and contractors put their corporate overheads and profits at risk in return for the promise that exceptional achievements will bring exceptional rewards from the client. Invariably, the client guarantees to pay the direct costs incurred by the consultants and contractors.

However, while the above has illustrated the possible advantages of the alliance model for the NBN project there remain a number of hurdles to overcome.

\section{Can the disadvantages that permeate the project alliance model be surmounted?}

There is a perception that this style of contracting engenders a lack of certainty from the Government, in costing and probity by diminishing participants' natural rights to go to court. This section will briefly consider of the disadvantages of the project alliance contract model and discuss whether these obstacles can be overcome.

\section{The relational style of project alliances}

The 'relational' style of the project alliance model may make it less appealing from the Government's perspective. This is because there is no perceived tendering on price. It is also in stark contrast with the tender process that appears to have commenced for the five

Rose, M (2011) 'Can project alliance contracts deliver Australia's national broadband network?', Australasian Journal of Construction Economics and Building, 11 (3) 68-81 
first release sites and the second release sites. An alliance contract would be subject to similar criticism to the PPP process; that clients spend money during the tendering process to clarify the costing because there is no fixed price. There is also the potential for perceived collusions amongst the tendering parties and a lack of value for money because it is difficult to cost the project. While these are valid concerns, they can potentially be overcome by a well-considered alliance and a shorter tendering period. While this time and cost saving can potentially be undermined by high training costs to coach the participant in the process provided participants are willing and able to accept the distribution of risks within the alliance culture - the contract structure can be better understood and managed because participants know what is required of them. In addition, there is an indication that this relational style may find favour with NBN Co, and vicariously the Government, because there appears to be a high level of engagement and commitment between participants so far, most notably in the Government's initial and active role in creating NBN Co to design and manage the project, rather than accepting any of the original tenders.

\section{Cost to establish a team}

An additional disadvantage is that there may be significant costs required to establish an integrated team structure where team members are chosen on a 'best for job' basis. This means that the success or failure of the job can turn on the dynamics of the team, as well as the succession of planning structures that are in place to account for natural workforce attrition. The idea behind this principle is that a culture is established that encourages and complements the outcomes of the project. This is a difficult problem to overcome because culture is intangible and may not be developed despite workshops and training. However, like all alliance agreements, with diligence, foresight and planning it would be possible to manage this risk in return for the rewards of a flexible business model.

\section{Probity}

Notwithstanding the integrated structure of a team, the accountability and transparency of this method may create a probity issue for Government. In part, this has already been the subject of comment from the Implementation Study and the Senate Select Committee, although concerns remain that the majority of this work may be in-house by NBN Co. This suggests that probity concerns may lie not with the type of contract model but rather with the transparency of NBN Co. This could be overcome by ensuring a suitably qualified probity auditor is engaged, financial audits of $100 \%$ open-book is undertaken, a public process and tender is held, and costs and targets are validated.

\section{Open-book compensation}

Despite the three-limbed approach to cost management, direct costs may be difficult to manage with an open-book approach. Despite best efforts to meet targets, there may be difficulty in limiting direct costs, and the Government would typically pay these amounts to the participant. Likewise, when monitoring costs, low costs must be maintained to ensure they are not at the expense of quality, particularly where the infrastructure is being designed to last for approximately 30-60 years. However, this could be overcome provided the agreement contains a 'fit for purpose' clause. This means that the participants would be required to rectify the work after the completion of the project, without increasing the direct cost of the work. It would then be up to NBN Co to reasonably adjust the risk-reward curve to ensure it is the participant and not the project that carries the risk.

\section{Is it legally binding?}

The criticism of the alliance model is that if legal liability is excluded, there may be no intention to create legal relations. This is because without a legally enforceable right, performance of the contract could be considered illusory where a participant fails to perform an obligation or discharge a duty. It has also been suggested that this mechanism is an attempt by participant's to oust the jurisdiction of the courts, and that the 'no blame, no dispute' clause might compromise a participant's professional indemnity insurance

Rose, M (2011) 'Can project alliance contracts deliver Australia's national broadband network?', Australasian Journal of Construction Economics and Building, 11 (3) 68-81 
(Abrahams \& Cullen 1998, p. 35). This seems to be a simple analysis of what is a highly sophisticated and complex agreement, where the parties expect to be held to the bargain. Notwithstanding the concerns raised about the court's jurisdiction, the court should not consider these clauses to be a collapse of the intention to contract. Rather, while the participants may not have the same bargaining power, they can be considered to have equivalent levels of business acumen and professional legal advisors to consider the risk allocation when negotiating the agreement. Ross (2010, p. 13) contends that parties do not waive or deny recourse to their natural rights so long as an alliance is properly structured and maintained, because the integrity of the mechanism to resolve legal disputes does not become a concern.

\section{Why the Project Alliance Model Could Achieve the NBN's Objectives}

The project alliance model complements the NBN's objectives because it encourages participants to focus on a shared business outcome: the completion of a fast and affordable broadband service for all Australians. It could achieve this by providing an innovative and unique way to overcome the difficulties particular to this project. It could achieve this by considering the three aspects of the NBN, concerning flexibility of managerial style and scope changes, open-book accounting and no disputes. The alliance model suggests a contractual approach that shares responsibility encourages solutions to accommodate variations, absorbs costs by sharing risks and motivates participants through the use of good faith to resolve disputes in a non-adversarial environment.

Alliance projects are reliant on setting expectations, working together to overcome each party's strengths and weaknesses, and a shared mutual goal. For the NBN project to succeed, all participants must work cooperatively towards the Government vision of providing high-speed, low-cost broadband to all Australians. The participants will need to be willing to share the risks and rewards if they are to bring the project in within time and under cost. Project alliances '....reflect(s) an emphasis on co-operation and dispute avoidance and reinforce the parties' objective to collaborate and develop innovative solutions for the success of the project without the threat of being sued.' (Abrahams \& Cullen, 1998, p. 35) By reflecting the behaviours that align with the NBN, an alliance contract would support the Government's view and enable the project to be delivered on time and budget.

While, the evolving nature of the NBN project will influence the contractual requirements, the alliance model is a contract whose behaviours coincide with the outcomes desired in the development of the broadband network. It supports the Government's aspirations in three ways:

First, by promoting flexibility, this would encourage collective responsibility on the part of contractor participants and suppliers to work together to resolve problems and share decision-making. This means that even when the project is faced with difficulties such as design variations required because of changing risk such as different topography, these risks would be absorbed into the project to avoid increasing the target cost or delaying project completion. This could drive innovation and solutions that may reduce risk and increase reward. Moreover, because all participants would be equal the alliance model would encourage decision-making on a 'best for job' basis.

Second, because all transactions are open-book, the costs are not fixed or included as estimates based on projected profit. The expenses are real and demonstrable. This would encourage innovation from the participants because in order for them to make a profit, and develop relationships to encourage further business contracts, they would have to find solutions that are auditable and cost effective. Supported by a style of open communication to encourage open cost accounting, this in turn would encourage good faith in relationships and trust as alliance behaviours. These behaviours in turn appear to replicate some of the

Rose, M (2011) 'Can project alliance contracts deliver Australia's national broadband network?', Australasian Journal of Construction Economics and Building, 11 (3) 68-81 
Government's preferences for the project; such as integrating new techniques and lessons learnt into the projects development (DBCDE 2010, pp. 10-11).

Third, because alliance contracting suggests an alternate way to view disputes, through inhouse management, rather than by reference to the courts, a different dynamic is created that demonstrates shared control, for shared outcomes. These three aspects can be managed under the alliance model, because alliance contracts encourage flexibility and shared responsibility. It is these behaviours, elicited by an alliance contract, which illustrates its unique compatibility with the aspirations of the Government's NBN project.

The alliance contract model can provide the legal framework to enable the deployment and delivery of an optical fibre broadband network that will found the highway to Australia's fast-paced digital future. In this context, the use of alliance contracts would support the Government's NBN aspiration to 'fundamentally transform the competitive dynamics of the Australian telecommunications sector' (Conroy, 2009, iii).

\section{References}

Abrahams, A. and Cullen, A. (1998) 'Project alliances in the construction industry', Australian Construction Law Newsletter, vol. 62

Bentley, P. (2009) 'The digital economy dance: Getting into step with government policy', Online Currents, vol. 23

Chew, A. (2004) 'Alliancing in delivery of major infrastructure projects and outsourcing services in Australia - An overview of legal issues', International Construction Law Review, p. 319

Conroy, S. (2009) Minister for Broadband, Communications and the Digital Economy, National Broadband Network: Regulatory Reform for the $21^{\text {st }}$ Century, discussion paper

DBCDE (2010) National Broadband Network Implementation Study, Department of Broadband, Communication and the Digital Economy

DBCDE (2011d) Why is it important?, Department of Broadband, Communication and the Digital Economy, http://www.nbn.gov.au/for-households/why-is-it-important/, accessed 12 September 2011

$\begin{array}{lllll}\text { Heydon, G. (2009d) GPON } v \text { Point to Point } & \text { Computer } & \text { World } \\ \text { http://www.computerworld.com.au/article/324177/gpon vs point point, } & \text { accessed } & 12\end{array}$ September 2011

Jones, D. (2001) 'Keeping the options open: Alliance and other forms of relationship contracting with government', Building and Construction Law, vol.17

Liew K 2009, "Next generation broadband regulation: NBN Co. and the government's new role in the market', Communications Law Bulletin, 29 (3), 19-21

Lynch, G. (2010) 'Telstra wrings $\$ 11$ billion out of NBN Co pact', Communications Day, vol. June, p. 3767

National Broadband Network Companies Act 2011 (Cth)

NBN Co (2011a) NBN Co and Optus Sign Binding Agreement, media release, http://www.nbnco.com.au/news-and-events/news/nbn-co--optus-sign-binding-

agreement.html, accessed 12 September 2011

NBN Co (2011b) NBN Co \& Silcar Reach Agreement to Deliver Value-for-Money Fibre Rollout, media release http://www.nbnco.com.au/news-and-events/news/nbnco-silcar-reachagreement-to-deliver-value-for-money-fibre-rollout.html, accessed 12 September 2011 
NBN Co (2010a) NBN Co Announces Next Rollout Locations, http://www.nbnco.com.au/assets/media-releases/2010/second-release-08-jul-10.pdf, accessed 12 September 2011

NBN Co (2011c) NBN Co Looks for Greater Value from Construction Tender, media release, http://www.nbnco.com.au/news-and-events/news/nbn-co-looks-for-greater-value-fromconstruction-tender.html, accessed 12 September 2011

NBN Co (2010b) NBN Co and Telstra reach Heads of Agreement, http://www.nbnco.com.au/ assets/media-releases/2010/nbnco-media-release-telstra-heads-of-agreement-20-jun-10.pdf , accessed 12 September 2011

Optus (2007a) Elders and Optus to Build Rural and Regional Broadband Network, media release, http://www.optus.com.au/aboutoptus/About+Optus/Media+Centre/Media+Releases /2007/Elders+and+Optus+to+build+rural+and+regional+broadband+network, accessed 12 September 2011

Prime Minister, Premier of Tasmania and Minister of Broadband (2009b) Tasmania First to Receive Superfast Broadband, media release, http://www.minister.dbcde.gov.au/media /media releases /2009/023, accessed 12 September 2011

Prime Minister, Treasurer, Minister for Finance and Minister for Broadband (2009a) New National Broadband Network, media release, Error! Hyperlink reference not valid., accessed 12 September 2011

Prime Minister, and Minister for Broadband (2009c) Tasmanian NBN Co Limited Established, media release, http://www.minister.dbcde.gov.au/media/media releases/2009/075, accessed 12 Sep 2011

Ross, J. (2010) 'Introduction to Project Alliancing (on engineering and construction projects), Sydney, 30 April 2003

Select Committee on the National Broadband Network (2010c) Answers to Questions on Notice, The Senate of the Parliament of Australia, Question No. 3, 15 April

Select Committee on the National Broadband Network (2010d) Final Report, The Senate of the Parliament of Australia, p. 9 and Ch.3 [3.1]-[3.60]

Select Committee on the National Broadband Network (2010e) Fourth Interim Report, The Senate of the Parliament of Australia, p. 73

Telecommunications Act 1997 (Cth)

Telstra (2011) Notice of Annual General Meeting, Explanatory Memorandum and Shareholder Voting Form, http://www.telstra.com.au/abouttelstra/download/document/tls 795- nom-em-voting.pdf accessed 12 September 2011

Thomas. T. (2007) 'Alliance contracts: Utility and enforceability', Building and Construction Law, vol. 23, 329

\section{Trade Practices Act 1974 (Cth)}

Wilton, P. (2010) 'It's business as usual in comms despite the spill', Communications Day, June, p.3779

\footnotetext{
1 BA/LLB (Hons). This article is based upon a paper the author submitted to the Melbourne University Masters of Law subject, Infrastructure Delivery A (13 September 2010)
}

Rose, M (2011) 'Can project alliance contracts deliver Australia's national broadband network?', Australasian Journal of Construction Economics and Building, 11 (3) 68-81 